\title{
Metabolic analysis of male servicemembers with transtibial amputations carrying military loads
}

\author{
Barri L. Schnall, MPT; ${ }^{1 *}$ Erik J. Wolf, PhD; ${ }^{1-2}$ Johanna C. Bell, MSE; ${ }^{1-2}$ Jeffrey Gambel, MD; ${ }^{1}$ Carolyn K. \\ Bensel, PhD $^{3}$ \\ ${ }^{1}$ Department of Orthopaedics and Rehabilitation, Walter Reed Army Medical Center, Washington, DC; ${ }^{2}$ Henry M. \\ Jackson Foundation for the Advancement of Military Medicine, Rockville, MD; ${ }^{3}$ U.S. Army Natick Soldier Research, \\ Development, and Engineering Center, Natick, MA
}

\begin{abstract}
For servicemembers who have sustained amputations and wish to return to Active Duty, performing common military tasks is essential. The purpose of this study was to examine the metabolic requirements of servicemembers with transtibial amputations wearing a loaded rucksack and walking at a steady speed. We tested 12 servicemembers with unilateral transtibial amputations and 12 uninjured controls on a treadmill at two walking speeds $(1.34$ and $1.52 \mathrm{~m} / \mathrm{s})$ while they carried a $32.7 \mathrm{~kg}$ load. Oxygen consumption was recorded. Results showed that metabolic demand for the injured servicemembers was significantly higher $(8.5 \%$ at $1.34 \mathrm{~m} / \mathrm{s}$ and $10.4 \%$ at $1.52 \mathrm{~m} / \mathrm{s}$ ) than for controls. An understanding of energy expended during load carriage by this study population is critical for decisions regarding return-to-duty requirements. Although significant differences existed between uninjured controls and those with amputations, it is important to note that those differences are less than previously published. This finding, coupled with the fact that servicemembers with transtibial amputations have redeployed, implies that, despite statistical significance, results may not be clinically relevant. Future work should include more taxing conditions to identify a threshold for potential limitations.
\end{abstract}

Key words: Borg Rating of Perceived Exertion, energy consumption, limb loss, load carriage, locomotion, military, return to duty, transtibial, treadmill, unilateral.

\section{INTRODUCTION}

All Active Duty U.S. Army servicemembers with major limb loss must eventually enter a service-specific
Medical Evaluation Board (MEB) process as prescribed by Army Regulation 40-501 [1]. For soldiers who have sustained amputations and wish to return to Active Duty, it is essential that they be able to perform common soldier tasks, such as marching with loads in different field environments. As a result of Operations Iraqi Freedom (OIF) and Enduring Freedom (OEF), the U.S. military is caring for an increased number of traumatically injured servicemembers with major limb loss. Of 1,337 servicemembers with major limb amputation, 118 have remained Active Duty or Active Reserve, including 30 who have redeployed to Iraq or Afghanistan [2]. There is renewed emphasis on supporting servicemembers with amputations who wish to return to duty, as many of those injured supporting OIF/OEF have much-needed soldier skills and valuable experience. In a challenging recruiting environment, it is

\footnotetext{
Abbreviations: MEB $=$ Medical Evaluation Board, MOLLE $=$ modular lightweight load-carrying equipment, $\mathrm{OEF}=$ Operating Enduring Freedom, OIF = Operation Iraqi Freedom, RPE = Rating of Perceived Exertion, TTA = transtibial amputation, $\mathrm{VO}_{2}=$ rate of oxygen consumption.

*Address all correspondence to Barri L. Schnall, MPT; Military Advanced Training Center, Center for Performance \& Clinical Research, America Building (\#19), B-322, Walter Reed National Military Medical Center, 8901 Wisconsin Ave, Bethesda, MD 20889-5600; 301-400-2096.

Email: barri.schnall@med.navy.mil

http://dx.doi.org/10.1682/JRRD.2011.04.0075
} 
especially important to retain capable, experienced, and motivated military personnel.

Little is known about the ability of servicemembers with amputations to meet military standards when executing soldier tasks involving physical activity. The MEB is therefore limited in the knowledge base it can apply to support a soldier's return to duty. This study is focused on acquiring information pertinent to one physical activity that dismounted troops are often required to perform: foot marches carrying military loads.

Because of advances in technology, including body armor, new weapons, and communication equipment, average loads carried by dismounted soldiers have tripled to upwards of $41 \mathrm{~kg}(90 \mathrm{lb})$ since the 18th century [3-4]. Reports on current U.S. operations in Afghanistan reveal that light infantry troops are carrying weights of $45 \mathrm{~kg}$ (100 lb) or more during dismounted operations [5-6]. One concern for soldiers who have lower-limb amputations and wish to return to duty is that, even without a load on the body, the reported energy expended in locomotion by amputees is greater than for individuals with intact limbs [7-9]. Because the conduct of foot marches by uninjured military carrying heavy loads entails a high metabolic cost [10], the additional physiological stress of load carriage may render servicemembers with amputations unable to participate successfully in military foot marches.

Experimentation to determine the energy cost entailed in walking with loaded military packs has not been performed on human subjects who have sustained lower-limb amputations. However, the most widely studied aspect of load carriage is the physiological cost to soldiers with intact limbs of walking while bearing a load $[3,11]$. The research has indicated an approximately linear relationship between load mass and energy expenditure, as measured by the rate of oxygen consumption $\left(\mathrm{VO}_{2}\right)$ [12] Further, the relationship between energy cost and walking speed has been described as a simple exponential function, with energy expenditure increasing rapidly at speeds above about $0.8 \mathrm{~m} / \mathrm{s}(1.9 \mathrm{mi} / \mathrm{h})$ [13-14]. Based on the systematic manner in which energy cost increases as a function of walking speed, grade of the walking surface, body mass, and external load mass, equations have been established to predict the energy cost of load carriage in uninjured individuals [15-16].

The predictive equations and research studies establishing relationships between energy cost and variables relevant to load carriage have been used to develop guidance for Army field commanders in planning and executing foot marches [17]. The Army guidance suggests the load masses and march paces possible to complete marches of several hours without exhausting the troops. A recent study of uninjured servicemembers reports that wearing body armor alone significantly increases $\mathrm{VO}_{2}$ associated with walking at slow and moderate paces and negatively impacts physical work capacity [18]. The trade-offs that must be considered between the march speed and the weight carried in order to avoid loss of soldiers to exhaustion are also detailed. If soldiers who sustained unilateral, transtibial amputations (TTAs) returned to duties that entailed foot marches, they would be expected to participate in marches conducted in accordance with this guidance. There is a dearth of data on which to assess the likelihood that a servicemember with an amputation could successfully complete a loaded march under these conditions.

No service-wide military physical fitness test exists. Of the service-specific tests, objective testing of the workrelated fitness for military occupations is limited. The backpack run test is proposed by Vanderburgh and Flanagan because it measures aerobic fitness, along with militarily relevant load carriage [19]. Vanderburgh and Flanagan claim that the backpack run test eliminates body-mass bias of an unloaded run. One obvious drawback is the lack of empirical research related to injury risk with loaded running, especially in the amputee population.

The research on energy cost during ambulation in people with lower-limb amputations has been focused mainly on evaluating designs of prosthetic devices [8,2021]. The test conditions involved lightweight clothing only; backpacks and other load-carriage equipment have not been used. In some of this research, uninjured subjects have been evaluated for control comparison. These studies conclude that people with amputations generally consume more energy than nondisabled controls. The differences between the two groups are affected by a number of variables, including the level of amputation, the prosthetic device worn, and the physical condition of the individuals [9,22]. Energy costs for people with unilateral lower-limb amputations have been reported to range from about 20 percent to more than 60 percent higher than those without limb loss during walking trials conducted at experimenter-determined (forced) speeds [7-8]. When walking speed is selected by the individual rather than imposed by the experimenter, people with amputations tend to walk at a slower pace than uninjured subjects. Energy costs of people with amputations are still higher than those without limb loss, but the differences in 
energy costs between the two groups are reduced somewhat compared with walking at forced speeds [7].

The primary objective of this study was to quantify and compare the energy expended by servicemembers with no limb loss and those with a unilateral TTA while walking at two military foot-march speeds and carrying a military approach load. We hypothesized that those with unilateral TTA would expend more energy during locomotion at each march speed than servicemembers without limb loss. A secondary objective was to evaluate the utility of the Borg Rating of Perceived Exertion (RPE) [23-24] scale in this environment.

\section{METHODS}

Twenty-four male subjects completed the required testing for this study, with 12 subjects who had sustained unilateral TTAs and 12 subjects with no limb loss (demographics in Table 1). The study participants who did not have amputations were U.S. Army enlisted personnel recruited from the U.S. Army Soldier Center, Natick, Massachusetts. These individuals were volunteers from among the enlisted personnel assigned to serve as human research volunteers for studies conducted by U.S. Army Natick Soldier Research, Development, and Engineering Center and other organizations located at the U.S. Army Soldier Center. The control participants traveled to Walter Reed Army Medical Center for the purpose of taking part in this study.

Volunteers with unilateral TTAs were recruited from among current military servicemembers (Regular Army, Army Reserve, or National Guard). Individuals with TTAs are followed regularly in physical therapy and in the Physical Medicine and Rehabilitation Amputee Clinic of Walter Reed, where they were informed of the study. Inclusion criteria for the subjects consisted of the ability to tolerate treadmill walking at multiple speeds under a load of up to $32.7 \mathrm{~kg}$, active military status or coverage

Table 1.

Subject demographics.

\begin{tabular}{|c|c|c|c|}
\hline Subjects & $\begin{array}{l}\text { Age } \\
\text { (yr) }\end{array}$ & $\begin{array}{l}\text { Height } \\
\text { (cm) }\end{array}$ & $\begin{array}{l}\text { Weight } \\
\text { (kg) }\end{array}$ \\
\hline Control $(n=12)$ & $20.9 \pm 2.8$ & $179.5 \pm 5.2$ & $83.2 \pm 9.2$ \\
\hline $\begin{array}{l}\text { Servicemembers } \\
\text { with TTA }(n=12)\end{array}$ & $26.9 \pm 5.5$ & $182.1 \pm 6.2$ & $93.7 \pm 19.3$ \\
\hline
\end{tabular}

under a serving family member's healthcare plan, and age between 18 and 35 years. Inclusion criteria for the subjects with TTAs also included at least 6 months of ambulation. Exclusion criteria included a history of medical conditions preventing cardiovascular training and comorbidities that did not permit safe, painless, independent walking. All subjects with TTAs wore their preferred energy-storing and return feet and were tested in their current socket, whether it was check (temporary) or definitive (permanent) (TTA demographics, Table 2). Residuallimb health was unremarkable as far as skin integrity and healing. One subject reported heterotopic ossification that did not limit function; three others reported decreased or increased sensitivity of the residuum.

Testing was conducted over 2 days to ensure that subjects did not fatigue. Subjects were asked to refrain from eating large meals before testing and also not to ingest any caffeine on the testing day. Subjects were fitted with a Polar heart rate monitor (Lake Success, New York) and metabolic mask. Data were collected using a COSMED K4b ${ }^{2}$ metabolic unit (Rome, Italy) that was calibrated immediately prior to use. Calibration was performed according to manufacturer's specifications, which included room air, reference gas, delay, and turbine calibrations. Collection began while the subjects rested for $5 \mathrm{~min}$, followed by $10 \mathrm{~min}$ of walking on a treadmill while wearing a rucksack. The subjects continued to be monitored while they rested again.

Table 2.

Demographics of subjects with transtibial amputations.

\begin{tabular}{cllc}
\hline $\begin{array}{c}\text { Subject } \\
\#\end{array}$ & Socket & \multicolumn{1}{c}{ Foot } & $\begin{array}{c}\text { Time from } \\
\text { Amputation } \\
\text { (yr) }\end{array}$ \\
\hline 1 & Definitive & VSP $^{*}$ & 3.3 \\
7 & Definitive & Ceterus $^{*}$ & 0.7 \\
8 & Definitive & unknown $^{*}$ & 5.0 \\
10 & Definitive & VSP $^{*}$ & 0.4 \\
11 & Check & Renegade $^{\dagger}$ & 0.8 \\
12 & Check & VSP $^{*}$ & 0.6 \\
13 & Definitive & Ceterus $^{*}$ & 3.5 \\
14 & Definitive & VSP $^{*}$ & 0.5 \\
16 & Definitive & Ceterus $^{*}$ & 2.5 \\
18 & Definitive & Renegade $^{\dagger}$ & 1.4 \\
19 & Definitive & ${\text { Renegade } \mathrm{MX}^{\dagger}}^{\dagger}$ & 1.1 \\
21 & Check & VSP $^{*}$ & 0.5 \\
\hline${ }^{*}$ Össur; Reykjavic, Iceland. & & \\
${ }^{\dagger}$ Freedom Innovations, LLC; Irvine, California. & \\
\hline \hline
\end{tabular}


The resting stage was terminated in 5 min if subjects were within 10 beats/min of their baseline resting measures. Collection continued until resting measures met the criterion for cessation.

Servicemembers were tested at two walking speeds, which were randomized between the two testing days. In consonance with military situations in which march pace is not under control of the individual soldier, the speeds tested in this study were investigator-controlled. Walking was performed at speeds of $1.34 \mathrm{~m} / \mathrm{s}(3.0 \mathrm{mi} / \mathrm{h})$ and at $1.52 \mathrm{~m} / \mathrm{s}(3.4 \mathrm{mi} / \mathrm{h})$, which are in the mid-range and on the high end, respectively, of speeds of military foot marches [17]. Both speeds are within the ranges tested in previous studies of energy costs associated with amputee locomotion $[8,20-21]$ and with load carriage by soldiers [25]. Walking was performed on a medical-grade treadmill (Woodway PPS 55 Med Treadmill; Waukesha, Wisconsin). The treadmill was set to the horizontal position.

At each speed, servicemembers who had unilateral TTAs and soldiers with intact limbs were outfitted in clothing and equipment, including a rucksack, that reflected the components and the weight of an infantry rifleman's approach march load. This load configuration has been used in past research on the energy cost of military load carriage $[11,25]$. The weights of the loads carried by riflemen and other members of infantry squads vary with the mission, the threat, and the environment [4,17]. In this study, the weight of all items worn or carried on the body was $32.7 \mathrm{~kg}$ (72 lb), which is within the range of weights included in earlier studies of energy costs of military load carriage $[10,12,14]$. The weight was selected for use in the present study because it reflects published Army guidance for field commanders regarding load weights to be carried on a foot march. The guidance suggests that the mass of the fighting load, inclusive of all clothing and equipment on the body, not exceed $21.8 \mathrm{~kg}$ and that the mass of the approach march load not exceed $32.7 \mathrm{~kg}$, again inclusive of all items worn or carried on the body [17].

The approach march load included the basic outfit, a helmet, a weapon, and a ballistic protective vest, plus the load-carrying vest and the rucksack and frame of the current Army carriage equipment, the modular lightweight load-carrying equipment (MOLLE). Dummy rounds of ammunition and dummy grenades were placed in pockets and pouches attached to the front of the MOLLE vest, and a 1 qt, water-filled canteen was placed on the vest at waist level. The MOLLE rucksack was loaded with items that soldiers typically carry to achieve a weight of all rucksack components, including the load in the pack itself, of $10.9 \mathrm{~kg}$. The $32.7 \mathrm{~kg}$ weight of the approach march load configuration did not include the TTA volunteer's prosthesis, which was incorporated into the TTA volunteer's body weight.

Volume of oxygen was recorded throughout the period of treadmill walking. Data from the last 2 minutes of walking (assumed that the subject had achieved steady state) were averaged to yield the oxygen consumption (kilograms per milliliters per minute). A mean was obtained over this period and entered into the analysis. The Borg RPE [23-24] was recorded at the end of the walking test. The RPE is a 15-category scale, ranging from 6 to 20, used to rate perceived exertion from no exertion at all (i.e., rest) to maximum exertion. When administered in studies of load carriage, the ratings appear to reflect feelings of increased muscle tension and sensations from skin, tendons, and ligaments rather than a more generalized level of exertion [26]. To account for this, a discomfort questionnaire was completed at the end of each walking test in this study. The Discomfort Questionnaire is a schematic of the body where the subject reports discomfort in any segment using a 5-point scale ( 1 = no discomfort, 5 = extreme discomfort). The RPE and the Discomfort Questionnaire data in the present study were acquired to contrast results of servicemembers with no limb loss and those with a unilateral TTA.

\section{RESULTS}

For the slow speed, data from three of the servicemembers with TTAs and one control were omitted because of errors in the data collection equipment. In the fast condition, data from three servicemembers with TTAs and two controls were removed, secondary to the same equipment error. Data were evaluated for normality and determined to be non-normal. To evaluate for differences between groups, a Wilcoxon rank-sum test was used with significance set at $p=0.05$.

Metabolic results showed significant differences between groups at both speeds ( $p=0.03$ at $1.34 \mathrm{~m} / \mathrm{s}$ and $p=$ 0.04 at $1.52 \mathrm{~m} / \mathrm{s}$ ). Differences between speeds were also evaluated, with results showing the metabolic output while walking at $1.52 \mathrm{~m} / \mathrm{s}$ to be significantly greater than at $1.34 \mathrm{~m} / \mathrm{s}(p<0.001$, Figure 1).

Results for the RPE (Figure 2) failed to show a significant difference between the servicemembers with TTAs and 


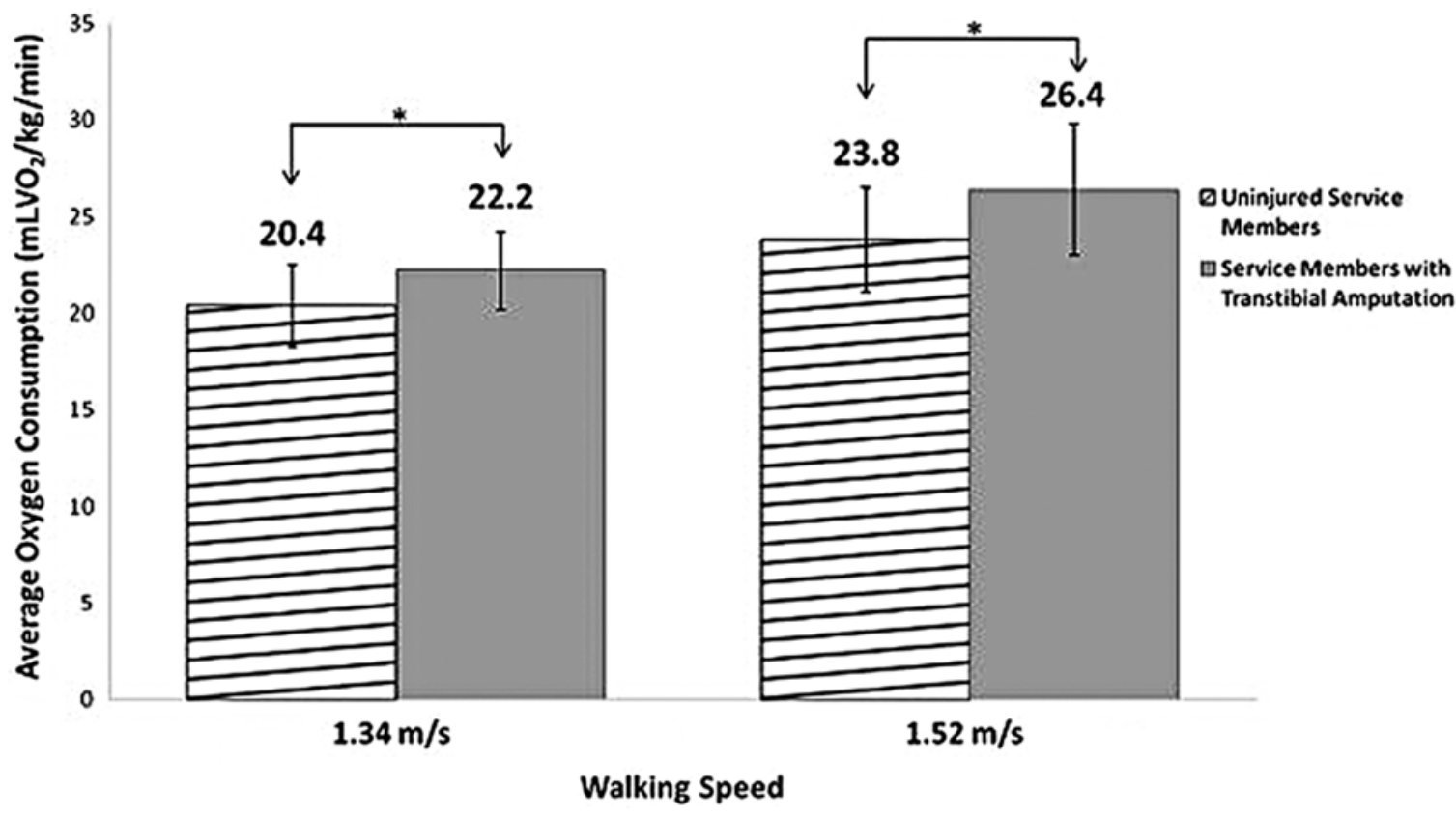

Figure 1.

Oxygen consumption ( $\mathrm{mL} \mathrm{VO}_{2} / \mathrm{kg} / \mathrm{min}$ ) for servicemembers with transtibial amputations and uninjured servicemembers while carrying $32.7 \mathrm{~kg}$ load and walking on treadmill at two speeds $(1.34 \mathrm{~m} / \mathrm{s}$ and $1.52 \mathrm{~m} / \mathrm{s})$. ${ }^{*}$ Significant difference of $p \leq 0.05$.

those with no injury at both speeds ( $p=0.08$ and $p=0.18$ for the slow and fast speeds, respectively). The ratings given also failed to show significant difference between speeds ( $p=0.49$ ), nor were RPE and oxygen consumption related (illustrated in Figure 3).

Discomfort Questionnaire scores reflected slight to moderate residual-limb discomfort in all but two subjects (2.3 \pm 0.49$)$ and slight low back discomfort in three of the subjects with TTAs. The control subjects reported a slight discomfort at a number of body sites: six reported lower back discomfort, three shoulder, three abdomen, and two pelvic. One control reported moderate discomfort because of the helmet. There was no trend related to testing speed in either group.

\section{DISCUSSION}

An understanding of the energy expended during load carriage by servicemembers with unilateral TTAs is critical for decisions regarding requirements for return to Active Duty. Results of this study showed that the $\mathrm{VO}_{2}$ for servicemembers who sustained unilateral TTAs is greater than that of their uninjured counterparts under the same load and speed conditions (Figure 1). Although significant differences existed between uninjured servicemembers and those with unilateral TTAs, it is important to note that those differences are less than previously published. Results from this study showed that metabolic demand for servicemembers with amputations was 8.5 percent and 10.4 percent higher than that for the controls at speeds of $1.34 \mathrm{~m} / \mathrm{s}$ and $1.52 \mathrm{~m} / \mathrm{s}$, respectively. An earlier study reported a 16 percent increase in unloaded metabolic effort between subjects with TTAs and those with no injury [27]. Additionally, in the earlier study, the selfselected pace of those with TTAs was 11 percent slower than the pace selected by uninjured subjects $(1.12 \mathrm{~m} / \mathrm{s}$ and $1.25 \mathrm{~m} / \mathrm{s}$, respectively). Self-selected pace has been reported to be the most efficient speed for people with lower-limb amputations [28-29]. The individuals with TTAs in the earlier study demonstrated a much higher metabolic demand than the servicemembers with TTAs in the current study, despite the fact that the current study entailed a faster speed and the additional stress of load carriage.

The high levels of metabolic efficiency displayed by the individuals in the current study who had TTAs compared with reports in the literature on individuals with 
amputations [8,27-29] may be attributable to differences in the populations under study. Much of the literature reports on individuals who are older, nonmilitary, or whose amputations may be associated with impaired health $[8-9,22,27,29]$. In addition, prostheses are prescribed based on activity level. The military population, having a high level of fitness, is prescribed prostheses that match that level of function.

With regard to the RPE [23-24] findings, the ratings given by the servicemembers in this study were not high (Figure 2). In the literature, $\mathrm{VO}_{2}$ was found to be significantly correlated with RPE in highly fit males [30]. However, in this study no relationship was found between the $\mathrm{RPE}$ and $\mathrm{VO}_{2}$ (illustrated in Figure 3). Typically, the $\mathrm{RPE}$ increases as the $\mathrm{VO}_{2}$ increases; however, this was not the case in this study. Additionally, servicemembers take pride in their strength and reject anything that can be perceived as weak. This is further supported by the Discomfort Questionnaire: except for three subjects reporting moderate discomfort in their residual limb, none of the servicemembers with amputations reported a pain level more than a slight discomfort anywhere on their person. Residual-limb discomfort often stems from limbvolume changes that can affect socket fit throughout the day. However, this sample of servicemembers does not appear to readily report discomfort, fatigue, or stress, regardless of the physical task imposed.

The results of this study can be explained by many factors, including age, preinjury physical fitness, and tolerance of servicemembers with amputations to an aggressive rehabilitation program. Servicemembers with unilateral TTAs demand more energy during loaded walking than their uninjured counterparts; however, the demand may not be prohibitive of returning to premorbid levels of activity or returning to duty. Metabolic demands for this group do not appear to be as great as the literature would lead one to believe. Findings indicate that those with TTAs may be able to successfully meet military job performance standards; as such, further investigation into servicemembers with all levels of amputation is warranted. Results may show that a young and otherwise healthy population that follows an aggressive rehabilitation program may be able to return to levels of metabolic efficiency close to preamputation levels.

One of the main limitations of this study was that the subjects may not have been taxed sufficiently during testing. The speeds were chosen based on Army regulations, but did not account for variable terrain over an extended period of time. In order to address this limitation in the future, treadmill testing should include inclines, as well as an increased duration of walking, to better represent

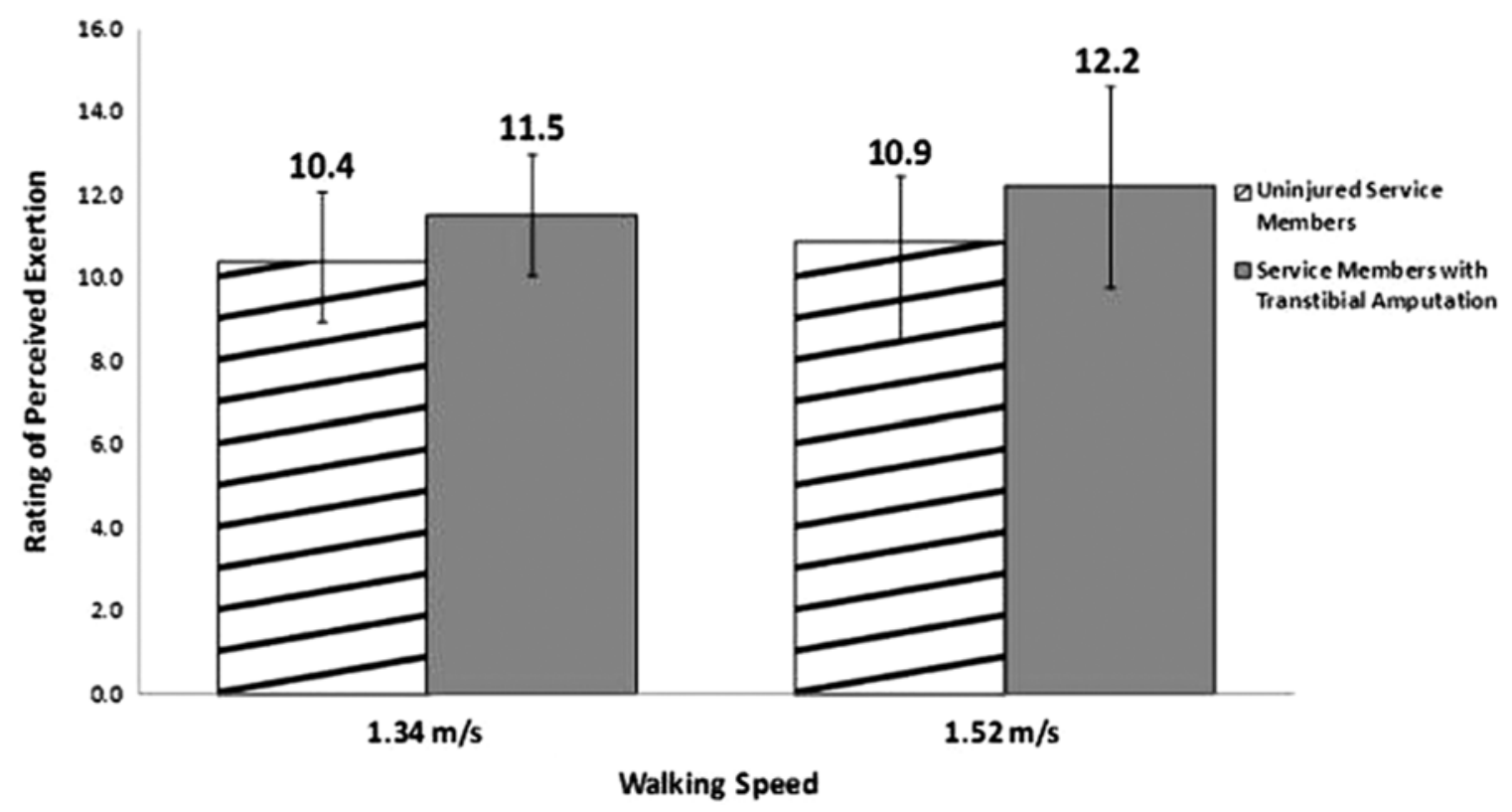

Figure 2.

Perceived exertion for servicemembers with transtibial amputations and uninjured servicemembers while carrying $32.7 \mathrm{~kg}$ load and walking on treadmill at two speeds $(1.34 \mathrm{~m} / \mathrm{s}$ and $1.52 \mathrm{~m} / \mathrm{s})$. 


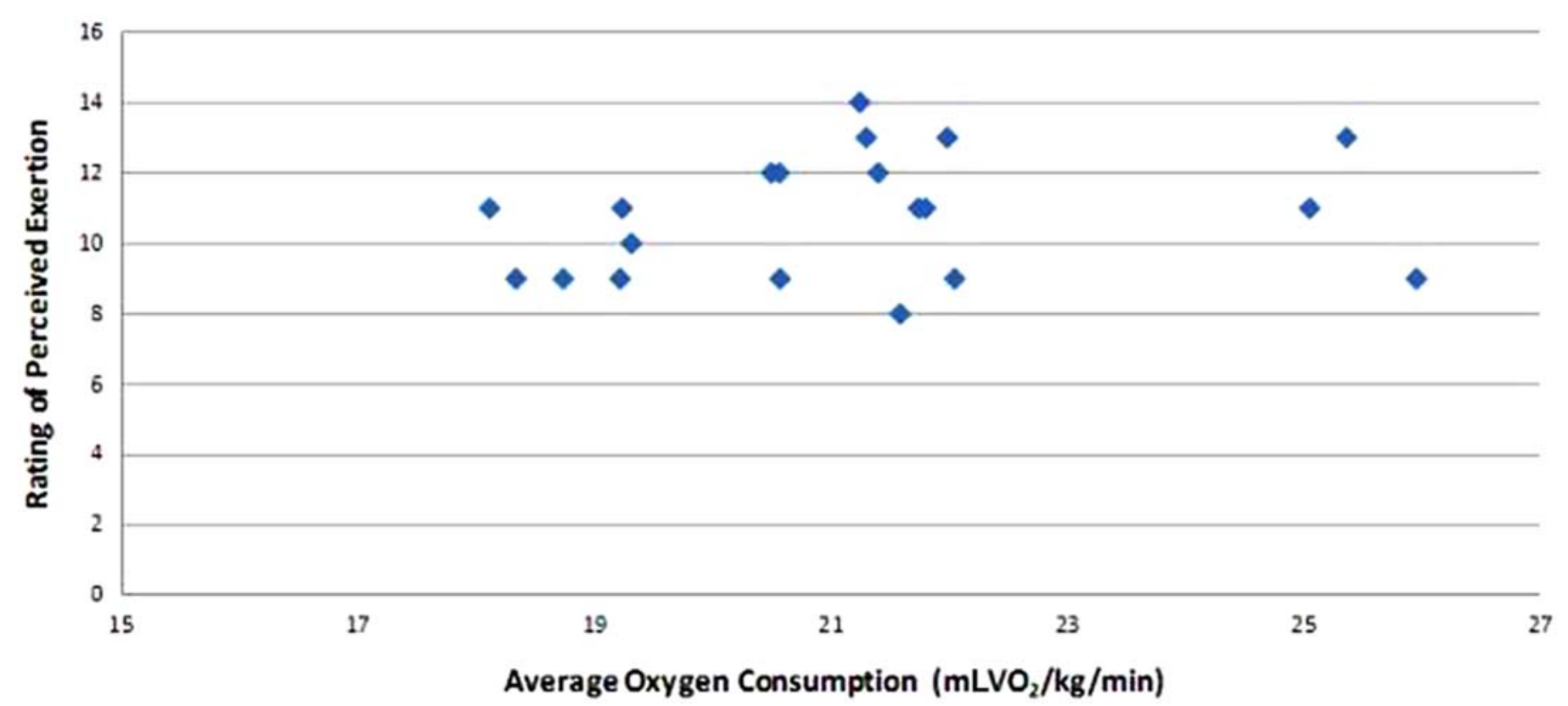

Figure 3.

Oxygen consumption ( $\mathrm{mL} \mathrm{VO} / \mathrm{kg} / \mathrm{min}$ ) compared to perceived exertion for servicemembers with transtibial ambutations and uninjured servicemembers while carrying $32.7 \mathrm{~kg}$ load and walking on treadmill at $1.34 \mathrm{~m} / \mathrm{s}$.

conditions experienced in theater. Additional speeds can also be considered. It is necessary to test load carriage capabilities during more demanding tasks (e.g., inclines and declines, uneven terrain, realistic wartime conditions [in a virtual environment], or performance of service-specific military tasks). Another improvement to this study would be to address prosthetic components by creating a study with different categories of feet to determine effects on biomechanics and energy efficiency, ultimately to inform manufacturers in order to make adjustable prostheses that accommodate to altered loads or terrain. Future research can also include individuals with a higher level of injury (e.g., transfemoral amputations). Based on the results of this research, it appears that the population of interest, specifically young, active, otherwise healthy servicemembers, may not be sufficiently represented in the current literature.

\section{CONCLUSIONS}

Functional studies of injured servicemembers are essential to provide guidance regarding those who wish to remain on Active Duty. The results from this study show that the energy consumption for servicemembers with TTA is significantly greater than that of uninjured servicemembers, although the results may not be clinically relevant. Compared with previously reported data on civilian populations, these participants are less burdened by their injury and perform closer to their uninjured counterparts. Servicemembers with TTA may be able to resume their former duty assignments or remain on Active Duty in new roles.

\section{ACKNOWLEDGMENTS}

\section{Author Contributions:}

Study concept and design: B. L. Schnall, C. K. Bensel, J. Gambel. Acquisition of data: B. L. Schnall, J. C. Bell, E. J. Wolf.

Analysis and interpretation of data: J. C. Bell, B. L. Schnall, E. J. Wolf, C. K. Bensel.

Drafting of manuscript: B.L. Schnall, J. C. Bell, E. J. Wolf. Critical revision of manuscript for important intellectual content: B. L. Schnall, J. C. Bell, E. J. Wolf, C. K. Bensel, J. Gambel.

Financial Disclosures: The authors have declared that no competing interests exist.

Funding/Support: This material was based on work supported by the U.S. Army Medical Research and Materiel Command (award W81XWH-06-2-0073).

Additional Contributions: The authors would like to acknowledge the Military Amputee Research Program for supporting this research and the U.S. Army Natick Soldier Research, Development, and Engineering 
Center for recruitment of control subjects. The authors would like to thank Ben Darter, PT, $\mathrm{PhD}$, for his contribution to data analysis methodology. The authors would especially like to thank the servicemembers for their willingness to volunteer for this protocol. Ms. Schnall is now with the Military Advanced Training Center, Center for Performance \& Clinical Research.

Institutional Review: The study was approved by the local institutional review board and conducted in accordance with Federal Policy for the Protection of Human Subjects, United States. Department of Defense, 32 CFR Part 219. All participants gave informed consent.

Participant Follow-Up: The authors do not plan to inform participants of the publication of this study unless specifically requested.

Disclaimer: The views expressed in this article are those of the authors and do not necessarily reflect the official policy or position of the Department of the Army, Department of Defense, or the U.S. Government.

\section{REFERENCES}

1. Gambel J, Dessain E, Fowler P, Rhodes A, Mayoroga M. Returning to duty after major limb loss and the US military disability system. In: Pasquina PF, Cooper RA, editors. Care of the combat amputee. Falls Church (VA): Office of the Surgeon General; 2009. p. 53-66.

2. Walter Reed amputee database. Washington (DC): U.S. Army; 2011.

3. Knapik JJ, Reynolds KL, Harman E. Soldier load carriage: Historical, physiological, biomechanical, and medical aspects. Mil Med. 2004;169(1):45-56. [PMID:14964502]

4. Ehrlich R. Soldier's load. Soldier's Load Conference; 2000; Fort Benning, GA.

5. Task Force Devil Combined Arms Assessment Team. The modern warrior's combat load. Dismounted operations in Afghanistan, April-May 2003. Fort Leavenworth (KS): U.S. Army Center for Army Lessons Learned; 2003.

6. Baker P. GIs battle "ghosts" in Afghanistan. Washington Post. 2002 May 16.

7. Hoffman MD, Sheldahl LM, Buley KJ, Sandford PR. Physiological comparison of walking among bilateral aboveknee amputee and able-bodied subjects, and a model to account for the differences in metabolic cost. Arch Phys Med Rehabil. 1997;78(4):385-92. [PMID:9111458] http://dx.doi.org/10.1016/S0003-9993(97)90230-6

8. Nielsen DH, Shurr DG, Golden JC, Meier KC. Comparison of energy cost and gait efficiency during ambulation in below-knee amputees using different prosthetic feet-A preliminary report. J Prosthet Orthot. 1988;1(1):24-31. http://dx.doi.org/10.1097/00008526-198810000-00006

9. Ward KH, Meyers MC. Exercise performance of lowerextremity amputees. Sports Med. 1995;20(4):207-14. [PMID:8584846] http://dx.doi.org/10.2165/00007256-199520040-00001
10. Soule RG, Pandolf KB, Goldman RF. Energy expenditure of heavy load carriage. Ergonomics. 1978;21(5):373-81. [PMID:668676] http://dx.doi.org/10.1080/00140137808931734

11. Knapik J, Harman E, Reynolds K. Load carriage using packs: a review of physiological, biomechanical and medical aspects. Appl Ergon. 1996;27(3):207-16.

[PMID:15677062] http://dx.doi.org/10.1016/0003-6870(96)00013-0

12. Goldman RF, Iampietro PF. Energy cost of load carriage. J Appl Physiol. 1962;17:675-76. [PMID:13899836]

13. Cotes JE, Meade F. The energy expenditure and mechanical energy demand in walking. Ergonomics. 1960;3(2):97-119. http://dx.doi.org/10.1080/00140136008930473

14. Hughes AL, Goldman RF. Energy cost of "hard work". J Appl Physiol. 1970;29(5):570-72. [PMID:5474847]

15. Givoni B, Goldman RF. Predicting metabolic energy cost. J Appl Physiol. 1971;30(3):429-33. [PMID:5544128]

16. Pandolf KB, Givoni B, Goldman RF. Predicting energy expenditure with loads while standing or walking very slowly. J Appl Physiol. 1977;43(4):577-81. [PMID:908672]

17. Department of the Army. Foot marches. Washington (DC): Department of the Army; 1990.

18. Ricciardi R, Deuster PA, Talbot LA. Effects of gender and body adiposity on physiological responses to physical work while wearing body armor. Mil Med. 2007;172(7):743-48. [PMID:17691688]

19. Vanderburgh PM, Flanagan S. The backpack run test: a model for a fair and occupationally relevant military fitness test. Mil Med. 2000;165(5):418-21. [PMID:10826392]

20. Gailey RS, Nash MS, Atchley TA, Zilmer RM, Moline-Little GR, Morris-Cresswell N, Siebert LI. The effects of prosthesis mass on metabolic cost of ambulation in non-vascular transtibial amputees. Prosthet Orthot Int. 1997;21(1):9-16. [PMID:9141121]

21. Lin-Chan SJ, Nielsen DH, Yack HJ, Hsu MJ, Shurr DG. The effects of added prosthetic mass on physiologic responses and stride frequency during multiple speeds of walking in persons with transtibial amputation. Arch Phys Med Rehabil. 2003;84(12):1865-71. [PMID:14669196] http://dx.doi.org/10.1016/j.apmr.2003.03.006

22. Waters RL, Perry J, Antonelli D, Hislop H. Energy cost of walking of amputees: the influence of level of amputation. J Bone Joint Surg Am. 1976;58(1):42-46. [PMID:1249111]

23. Borg GA. Perceived exertion. Exerc Sport Sci Rev. 1974; 2:131-53. [PMID:4466663] http://dx.doi.org/10.1249/00003677-197400020-00006

24. Borg GA. Psychophysical bases of perceived exertion. Med Sci Sports Exerc. 1982;14(5):377-81. [PMID:7154893] http://dx.doi.org/10.1249/00005768-198205000-00012 
25. Patton JF, Kaszuba J, Mello RP, Reynolds KL. Physiological responses to prolonged treadmill walking with external loads. Eur J Appl Physiol Occup Physiol. 1991;63(2):89-93. [PMID:1748110] http://dx.doi.org/10.1007/BF00235175

26. Goslin BR, Rorke SC. The perception of exertion during load carriage. Ergonomics. 1986;29(5):677-86. [PMID:3720724] http://dx.doi.org/10.1080/00140138608968302

27. Gailey RS, Wenger MA, Raya M, Kirk N, Erbs K, Spyropoulos P, Nash MS. Energy expenditure of trans-tibial amputees during ambulation at self-selected pace. Prosthet Orthot Int. 1994;18(2):84-91. [PMID:7991365]

28. Pepper M, Willick S. Maximizing physical activity in athletes with amputations. Curr Sports Med Rep. 2009;8(6): 339-44. [PMID:19904075]

29. Gonzalez EG, Corcoran PJ, Reyes RL. Energy expenditure in below-knee amputees: Correlation with stump length. Arch Phys Med Rehabil. 1974;55(3):111-19. [PMID:4817680]
30. Chen MJ, Fan X, Moe ST. Criterion-related validity of the Borg ratings of perceived exertion scale in healthy individuals: a meta-analysis. J Sports Sci. 2002;20(11):873-99. [PMID:12430990]

http://dx.doi.org/10.1080/026404102320761787

Submitted for publication April 20, 2011. Accepted in revised form October 11, 2011.

This article and any supplementary material should be cited as follows:

Schnall BL, Wolf EJ, Bell JC, Gambel J, Bensel CK. Metabolic analysis of male servicemembers with transtibial amputations carrying military loads. J Rehabil Res Dev. 2012;49(4):535-44.

http://dx.doi.org/10.1682/JRRD.2011.04.0075

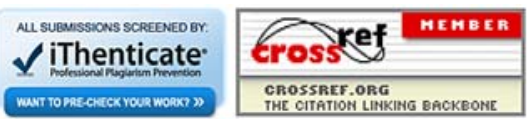


